\title{
Columnar/herringbone dual crystal packing of pyrenylsumanene and its photophysical properties
}

\author{
Binod Babu Shrestha ${ }^{1}$, Shuhei Higashibayashi ${ }^{* 1,2,3}$ and Hidehiro Sakurai ${ }^{* 1,2}$
}

\section{Full Research Paper}

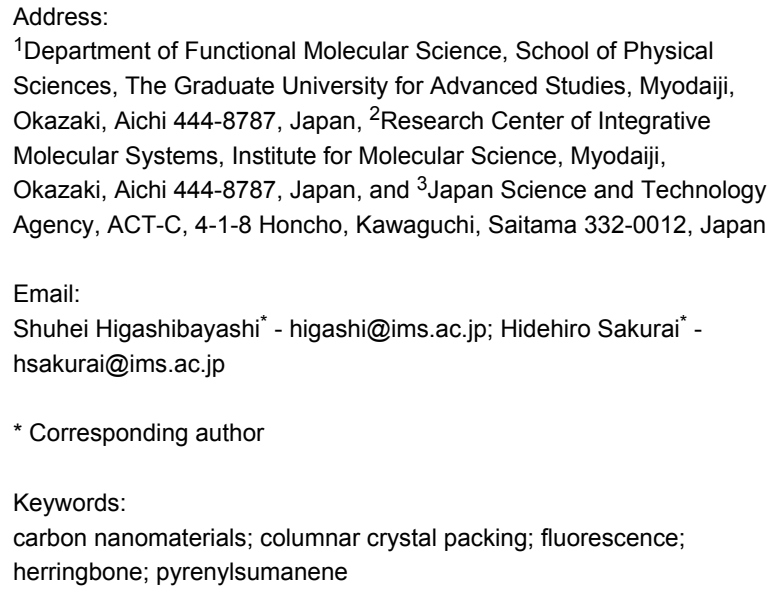

${ }^{1}$ Department of Functional Molecular Science, School of Physical Sciences, The Graduate University for Advanced Studies, Myodaiji, Okazaki, Aichi 444-8787, Japan, ${ }^{2}$ Research Center of Integrative Molecular Systems, Institute for Molecular Science, Myodaiji, Okazaki, Aichi 444-8787, Japan, and ${ }^{3} J a p a n$ Science and Technology Agency, ACT-C, 4-1-8 Honcho, Kawaguchi, Saitama 332-0012, Japan

\section{Email:}

Shuhei Higashibayashi* - higashi@ims.ac.jp; Hidehiro Sakurai* hsakurai@ims.ac.jp

* Corresponding author

Keywords:

carbon nanomaterials; columnar crystal packing; fluorescence; herringbone; pyrenylsumanene

Beilstein J. Org. Chem. 2014, 10, 841-847. doi:10.3762/bjoc. 10.80

Received: 16 December 2013

Accepted: 21 March 2014

Published: 11 April 2014

This article is part of the Thematic Series "Functionalized carbon-nanomaterials".

Guest Editor: A. Krueger

(C) 2014 Shrestha et al; licensee Beilstein-Institut. License and terms: see end of document.

\begin{abstract}
A single crystal of pyrenylsumanene was found to exhibit both columnar and herringbone crystal packing. The sumanene moieties form unidirectional columnar structures based on $\pi-\pi$ stacking while the pyrene moieties generate herringbone structures due to $\mathrm{CH}-\pi$ interactions. The absorption and emission maxima of pyrenylsumanene were both red-shifted relative to those of sumanene and pyrene, owing to the extension of $\pi$-conjugation. Monomer emission with high quantum yield (0.82) was observed for pyrenylsumanene in solution, while excimer-type red-shifted emission was evident in the crystalline phase.
\end{abstract}

\section{Introduction}

Buckybowls - bowl-shaped aromatic hydrocarbons - possess unique physical properties due to their curved $\pi$-conjugated systems [1-5]. One of these characteristic features is a columnar packing structure in the crystal state. Many buckybowls, including sumanene [2], exhibit columnar packing in which the bowl-shaped molecules are stacked in a convex-to-concave fashion, since this particular pattern results in more highly favored intermolecular $\pi-\pi$ interactions [1-13]. The columnar packing structures of buckybowls typically occur in two forms which are differentiated by the stacking of the columns: unidirectional (Figure 1a) and opposite (Figure 1b). These columnar structures allow buckybowls to exhibit specific solid-state properties, including high electron conductivity and solid-state emission [14-18]. In contrast, planar $\pi$-conjugated aromatic compounds tend to favour a herringbone packing structure (Figure $1 \mathrm{c}$ ) due to $\pi-\pi$ and $\mathrm{CH}-\pi$ interactions $[19,20]$. To date, buckybowl derivatives with planar aromatic substituents have not been well studied and thus we wished to examine the crystal 
a)

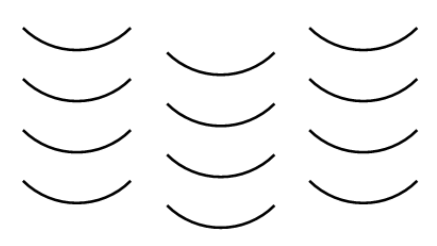

b)

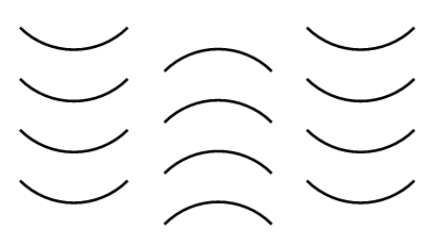

c)

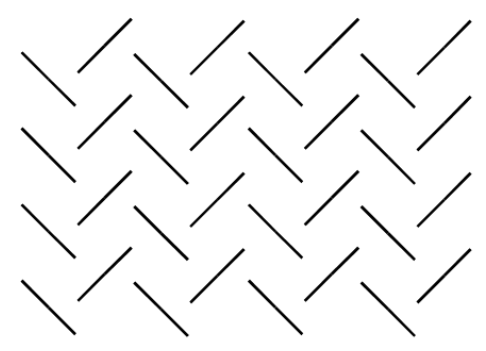

Figure 1: Columnar packing structures of buckybowls showing (a) unidirectional and (b) opposite structures, in addition to (c) the herringbone packing structure typical of planar $\pi$-conjugated compounds.

packing modes and solid-state properties of dual-nature compounds incorporating both bowl and planar structures. Pyrene was selected as the planar substituent when studying solid-state photophysical properties $[21,22]$ and herein we report the columnar/herringbone dual crystal packing of pyrenylsumanene (1) in addition to its photophysical properties.

\section{Results and Discussion}

Pyrenylsumanene (1) was prepared from iodosumanene [8] and pyreneboronic acid in $84 \%$ yield through a Suzuki-Miyaura cross-coupling reaction (Scheme 1). The preparation of iodosumanene was improved by using a catalytic amount of scandium (III)triflate $\left(\mathrm{Sc}(\mathrm{OTf})_{3}\right)$ with 6,6'-diiodo-2,2'dimethoxy-1,1'-binaphthol (DIH) [23] compared to the previously reported system of $\mathrm{AuCl}_{3}$ and $\mathrm{N}$-iodosuccinimide [8], resulting in an $80 \%$ yield.
Following synthesis of $\mathbf{1}$, a single crystal was obtained from $\mathrm{CH}_{2} \mathrm{Cl}_{2} / \mathrm{MeOH}$ solution, with the crystal structure shown in Figure 2. The bowl depth of $\mathbf{1}$ from the centroid of the rim carbons to the centroid of the benzene ring is $1.09 \AA$ (Figure 2b) and thus the bowl is slightly shallower than that of sumanene (1.11 A) [11]. The structure resulting from DFT calculations at the $\omega \mathrm{B} 97 \mathrm{XD} / 6-31 \mathrm{G}(\mathrm{d})$ level indicates that $\mathbf{1}$ has a greater bowl depth $(1.15 \AA)$ than sumanene $(1.13 \AA)$. This difference results from the effects of intermolecular interactions in the crystal state [9]. The X-ray data indicate that the dihedral angle between the sumanene and pyrene moieties is $41.4^{\circ}$ (Figure 2a). Most notably, 1 exhibits dual columnar and herringbone packing modes; the sumanene moiety undergoes columnar packing with convex-to-concave stacking, while the pyrene moiety shows herringbone packing with $\mathrm{CH}-\pi$ interactions (Figures 2c,d). The columns of $\mathbf{1}$ are arranged unidirectionally,

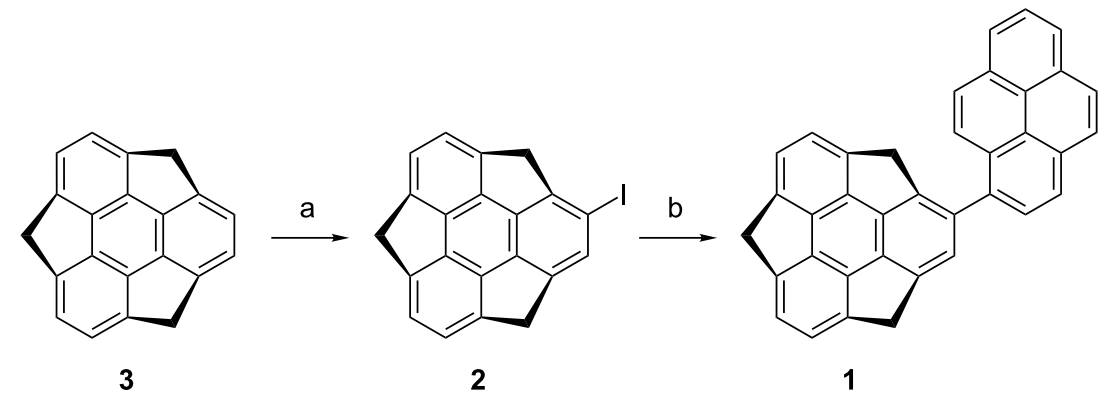

Scheme 1: Synthesis of pyrenylsumanene (1): (a) Sc(OTf) 3 (5 mol \%), DIH (100 mol \%), $\mathrm{CH}_{2} \mathrm{Cl}_{2}$, rt, $2.5 \mathrm{~h}$, yield $80 \%$; (b) palladium (II) acetate $(20 \mathrm{~mol} \%)$, 1-pyreneboronic acid $(150 \mathrm{~mol} \%)$, acetone/water $4: 1,40^{\circ} \mathrm{C}, 12 \mathrm{~h}$, yield $84 \%$. 
a)

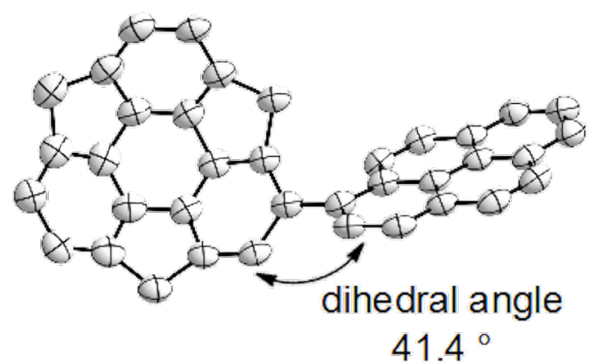

c)

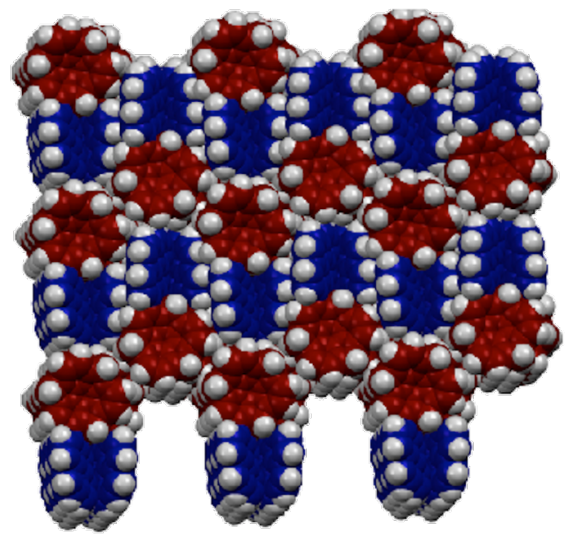

b)

\section{bowl depth}

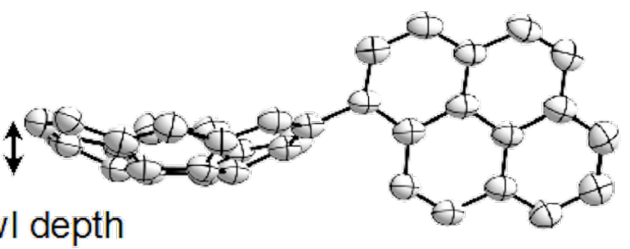

$1.09 \AA$

\section{d)}

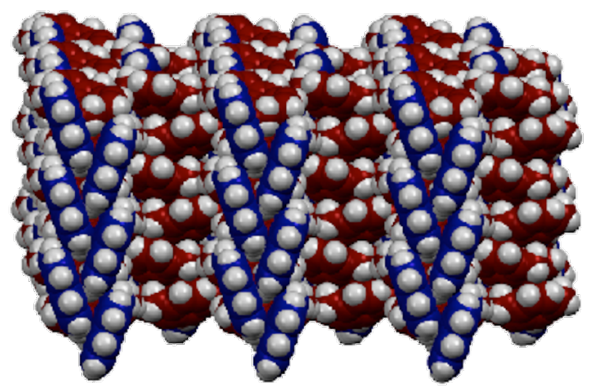

e)

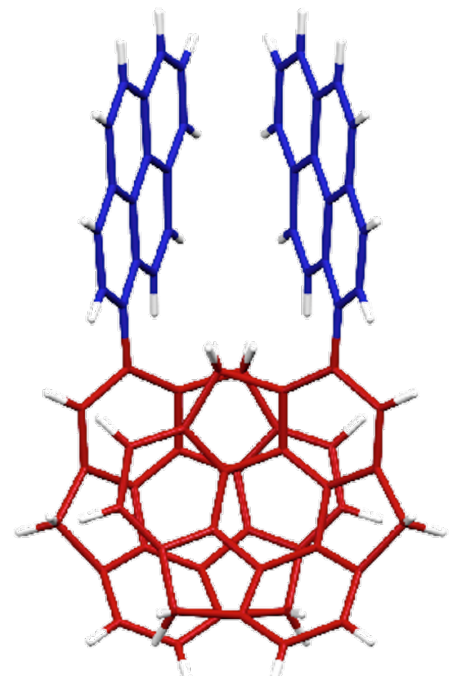

f)

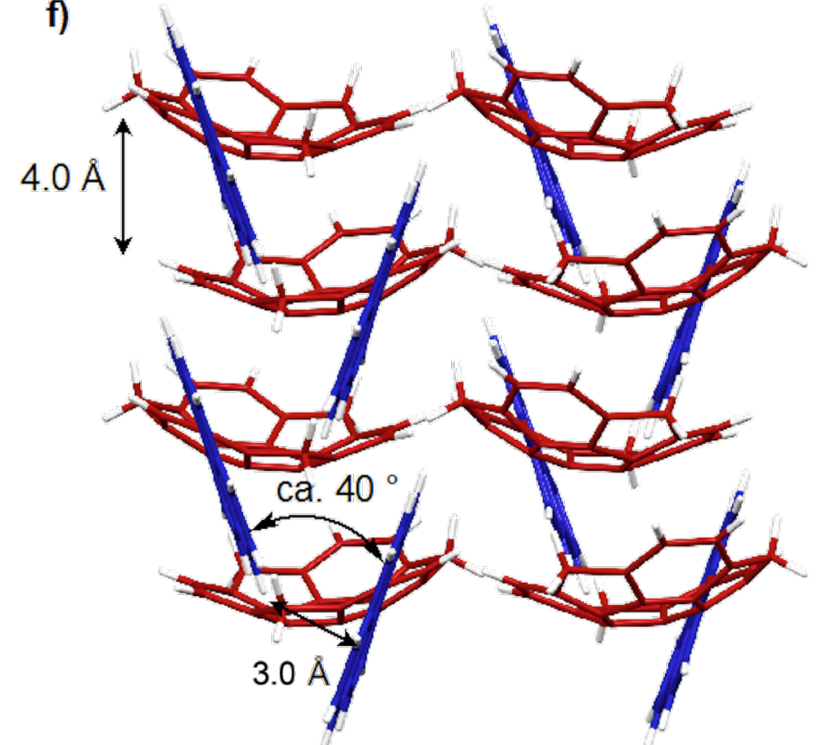

Figure 2: The X-ray crystal structure of 1, showing: (a) top view of the ORTEP drawing with $50 \%$ probability, b) side view, c) top view of the packing structure with the sumanene bowl in red and the pyrene substituent in blue, d) side view, e) top view of column stacking of enantiomers and f) side view of columns with a herringbone packing of the pyrene moiety due to $\mathrm{CH}-\pi$ interactions.

in the same manner as observed in sumanene and hexafluorosumanene (representing the type a stacking shown in Figure 1) [7,11]. Compound 1 possesses bowl chirality [9,24,25] and the crystal represents a racemic mixture in which the two enantiomers are stacked in columns alternating at $4.0 \AA$ intervals with side-to-side offsets (Figures 2e,f). In the herringbone arrangement of the pyrene moieties, the $\mathrm{CH}-\pi$ interactions occur at a distance of $3.0 \AA$ (Figure 1f). The $\pi-\pi$ stacking of pyrene moieties, however, is not evident in the arrangement. 

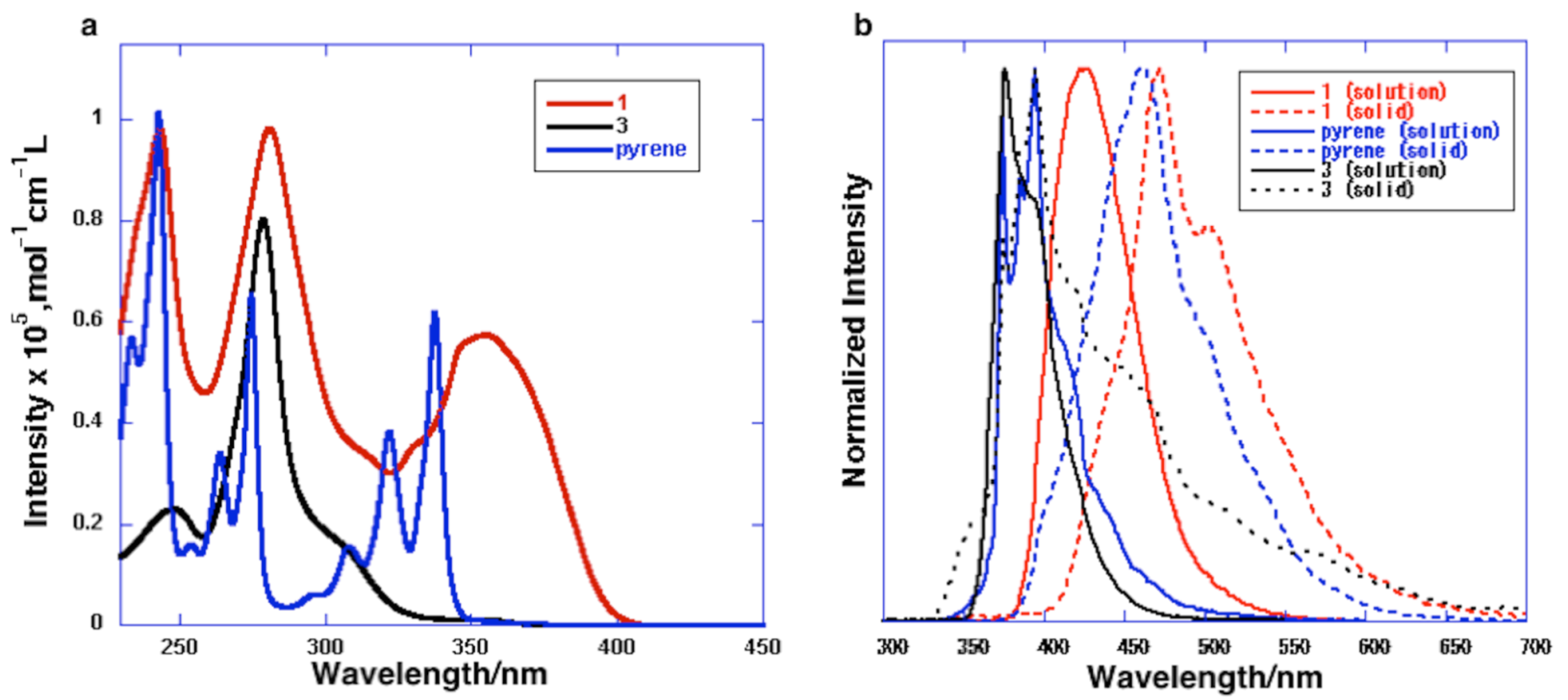

Figure 3: (a) Absorption spectra of 1, 3 and pyrene in $\mathrm{CH}_{2} \mathrm{Cl}_{2}$ solution $\left(1.0 \times 10^{-5} \mathrm{M}\right)$; (b) emission spectra of 1,3 and pyrene in $\mathrm{CH}_{2} \mathrm{Cl}_{2}$ solution (solid line) $\left(1.0 \times 10^{-5} \mathrm{M}\right)$ and in the solid state (dotted line).

The UV-vis absorption and emission spectra and maxima as well as the quantum yields of $\mathbf{1}, 3$ and pyrene in $\mathrm{CH}_{2} \mathrm{Cl}_{2}$ or in the solid state are summarized in Figure 3 and Table 1. The absorption maximum of $\mathbf{1}$ was evidently red-shifted relative to those of $\mathbf{3}$ and pyrene. The $355 \mathrm{~nm}$ absorption band of $\mathbf{1}$ was assigned to the HOMO-LUMO transition by TD-DFT calculations $(\omega \mathrm{B} 97 \mathrm{XD} / 6-31 \mathrm{G}(\mathrm{d}))$. DFT calculations also demonstrated that the HOMO and LUMO of $\mathbf{1}$ are primarily located on the pyrene moiety (Figure 4). The dihedral angle between the sumanene and pyrene moieties resulting from calculations was $48.2^{\circ}$. This angle causes some extension of the $\pi$-conjugation to the sumanene moiety, resulting in a narrower HOMO-LUMO gap and the observed red shift in absorption. The emission of $\mathbf{1}$ in solution is also red-shifted relative to those of $\mathbf{3}$ and pyrene, again owing to the $\pi$-extension. The emission of pyrene at $395 \mathrm{~nm}$ in solution is considered to result from the monomer form because of the low concentration, since pyrene is known to generate excimer emission at $480 \mathrm{~nm}$ at high concentrations $\left(>10^{-5} \mathrm{M}\right)$ [26,27]. The emission of 1 at $422 \mathrm{~nm}$ is also assigned to monomer emission. Compound 1 did not generate excimer emission in solution concentrations over the range of $10^{-4}-10^{-7} \mathrm{M}$ and, due to the poor solubility of this compound, spectra at concentrations above $10^{-4} \mathrm{M}$ could not be acquired. The emissions of 1 and pyrene in the solid state (at 473 and $463 \mathrm{~nm}$ ) were red-shifted relative to those observed for these compounds in solution. The red-shifted emission of pyrene in the solid state originates from the excimer state of the crystal $[26,27]$. In the herringbone packing of $\mathbf{1}$, the distance asso-

Table 1: Absorption, emission and quantum yield data for 1, 3 and pyrene.

\begin{tabular}{|c|c|c|c|}
\hline compound & $\begin{array}{c}\lambda_{\mathrm{abs}}(\mathrm{nm})^{\mathrm{a}} \\
\left(\varepsilon=1 \times 10^{5}, \mathrm{~mol}^{-1} \mathrm{~cm}^{-1} \mathrm{~L}\right)\end{array}$ & $\lambda_{\mathrm{em}}(\mathrm{nm})^{\mathrm{b}}$ & $\Phi^{\mathrm{C}}$ \\
\hline 1 (solution) & 243 (0.98), 280 (0.98), 355 (0.57) & 422 & 0.82 \\
\hline 3 (solution) & $278(0.80)$ & 375 & 0.02 \\
\hline pyrene (solution) & 242 (1.01), 274 (0.64), 337 (0.61) & 395 & $0.64^{d}$ \\
\hline 1 (solid) & - & 473 & 0.10 \\
\hline 3 (solid) & - & 395 & 0.03 \\
\hline pyrene (solid) & - & 463 & $0.68^{d}$ \\
\hline
\end{tabular}

aAbsorption spectra in $\mathrm{CH}_{2} \mathrm{Cl}_{2}\left(1.0 \times 10^{-5} \mathrm{M}\right)$; bemission spectra in $\mathrm{CH}_{2} \mathrm{Cl}_{2}\left(1.0 \times 10^{-5} \mathrm{M}\right)$ or in solid state. Excitation at $280 \mathrm{~nm}$ for $\mathbf{1}$ (solution) and $\mathbf{3}$ (solution and solid), $300 \mathrm{~nm}$ for 1 (solid), $270 \mathrm{~nm}$ for pyrene (solution and solid); crelative quantum yield in cyclohexane solution (5.0 $\times 10^{-7} \mathrm{M}$ ) with 9,10-diphenylanthracene as a standard or absolute quantum yield in solid state; ${ }^{d}$ reported quantum yield of pyrene in [26,27]. 


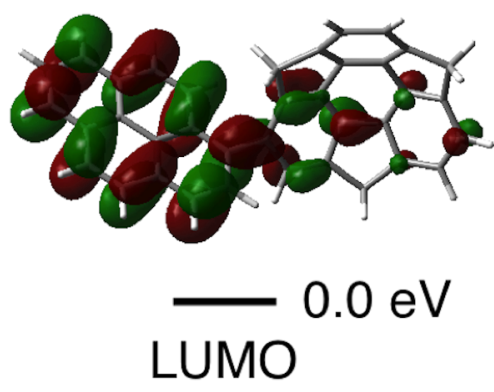

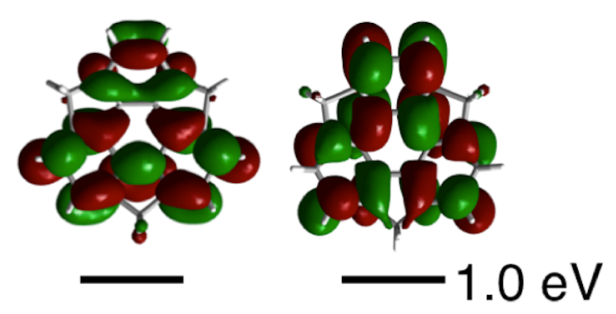

LUMO

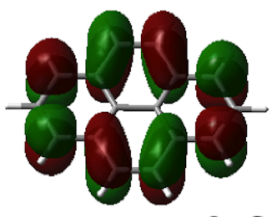

$0.2 \mathrm{eV}$

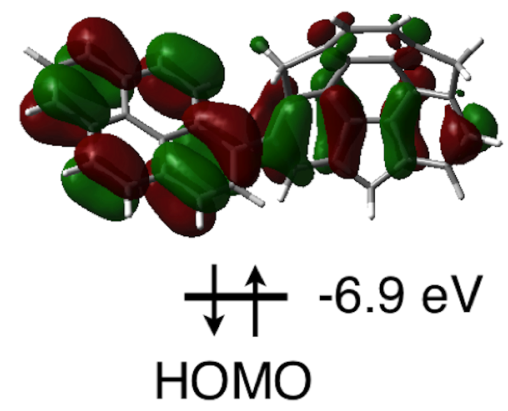

$\Delta E=6.9 \mathrm{eV}$

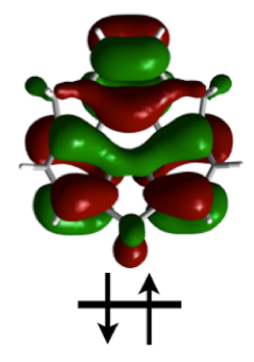

HOMO

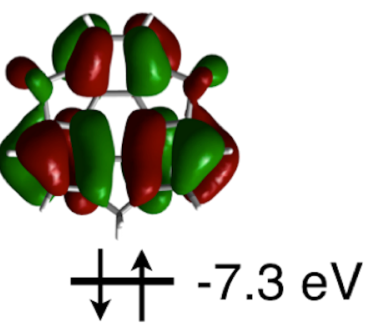

$\downarrow$ † $-7.3 \mathrm{eV}$

$\Delta E=8.3 \mathrm{eV}$

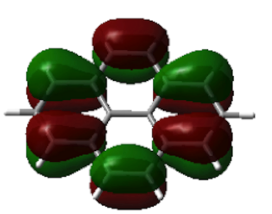

$\downarrow$ 十 $-7.1 \mathrm{eV}$

HOMO
$\Delta E=7.3 \mathrm{eV}$

\section{pyrene}

Figure 4: Calculated HOMO and LUMO orbitals and HOMO-LUMO gaps $(\Delta \mathrm{E})$ for 1, 3 and pyrene $(\omega B 97 \mathrm{XD} / 6-31 \mathrm{G}(\mathrm{d}))$.

ciated with the $\mathrm{CH}-\pi$ interaction is $3.0 \AA$ which is sufficiently close to form an excimer (Figure 2f). The angle of the pyrene moieties resulting from the $\mathrm{CH}-\pi$ interaction is approximately $40^{\circ}$ (Figure $2 \mathrm{f}$ ), which enables the partial $\pi-\pi$ interactions. Judging from the crystal features of $\mathbf{1}$, the red-shifted emission of $\mathbf{1}$ in the crystal is also assigned to the excimer state. The quantum yields of pyrene in solution and in the solid state are almost equal (0.64 and 0.68). In contrast, the quantum yield of $\mathbf{1}$ in the solid state $(0.10)$ is decreased significantly from that in solution (0.82). This exciton quenching may be due to the effect of the sumanene moiety, since the quantum yield of $\mathbf{3}$ is low both in solution and in the solid state.

\section{Conclusion}

The ability to predict the crystal packing of organic molecules is important in the design of functional organic compounds but remains challenging. In this regard, the columnar structure of buckybowl crystals resulting from convex-concave intermolecular $\pi-\pi$ interactions is expected to be quite predictable and to serve as a directing force to provide specific crystal structures $[16,17]$. The present study demonstrates the promising possi- bility of utilizing the sumanene moiety as a directing group to obtain specific crystal structures.

\section{Experimental \\ General}

UV-visible absorption spectra were recorded on a JASCO V-670 spectrometer. Fluorescence spectra were recorded on a JASCO FP6500 spectrometer. Melting points were determined on a Standford Research Systems MPA 100 and were uncorrected. Infrared (IR) spectra were recorded on a JASCO FT IR-4100 spectrometer. ${ }^{1} \mathrm{H}$ and ${ }^{13} \mathrm{C}$ NMR spectra were measured on a JEOL JNM-ECS (Delta V5.0) 400 spectrometer at $23{ }^{\circ} \mathrm{C}$ at $400 \mathrm{MHz}$ and $100 \mathrm{MHz}$. $\mathrm{CDCl}_{3}$ was used as a solvent and the residual solvent peaks were used as an internal standard ( ${ }^{1} \mathrm{H}$ NMR: $\mathrm{CDCl}_{3} 7.24$ ppm; ${ }^{13} \mathrm{C}$ NMR: $\mathrm{CDCl}_{3} 77.00 \mathrm{ppm}$ ). Elemental analyses were measured on a J-Science Micro corder JM10. Mass spectra were measured on a JEOL JMS-777V spectrometer using electron impact mode (EI). Gel-permeation chromatography (GPC) was performed on JAIGEL $1 \mathrm{H}$ and $2 \mathrm{H}$ using a JAI Recycling Preparative HPLC LC-908W with $\mathrm{CHCl}_{3}$ as eluent. TLC analysis was performed using Merck silica gel 
60 F254. All reagents and solvents were commercially purchased from Kanto, Wako, Nacalai, and Kishida and further purified according to the standard methods, if necessary.

\section{Synthesis of 2}

Sumanene (3) (100 mg, $0.378 \mathrm{mmol}), 6,6$ '-diiodo-2,2'dimethoxy-1,1'-binaphthol (DIH) (144 mg, $0.378 \mathrm{mmol})$ and scandium(III) triflate $(9.3 \mathrm{mg}, 0.0189 \mathrm{mmol})$ were placed in a $50 \mathrm{~mL}$ dry flask under an $\mathrm{Ar}$ atmosphere. Dry $\mathrm{CH}_{2} \mathrm{Cl}_{2}(37 \mathrm{~mL})$ was then added. The reaction mixture was allowed to stir for $2.5 \mathrm{~h}$ at $\mathrm{rt}$. The completion of reaction was monitored by TLC ( $100 \%$ cyclohexane). The reaction was quenched by saturated aq. $\mathrm{Na}_{2} \mathrm{~S}_{2} \mathrm{O}_{3}$ and the mixture was extracted with $\mathrm{CH}_{2} \mathrm{Cl}_{2}$ $(50 \mathrm{~mL} \times 3)$. The combined organic extracts were washed with water, brine, dried over $\mathrm{Na}_{2} \mathrm{SO}_{4}$, filtered through Celite, and evaporated. The residue was purified by GPC to afford pure 2 (106 mg, 80\%) with recovery of $\mathbf{3}(10.0 \mathrm{mg})$.

\section{Synthesis of 1}

Iodosumanene (2) $(10.0 \mathrm{mg}, 0.025 \mathrm{mmol})$, pyreneboronic acid (7.8 mg, $0.038 \mathrm{mmol})$ and palladium(II) acetate $(1.2 \mathrm{mg}, 0.0051$ $\mathrm{mmol})$ were placed in a $50 \mathrm{~mL}$ dry test-tube. Dry acetone $(8$ $\mathrm{mL})$ and water $(4 \mathrm{~mL})$ was then added. The reaction mixture was allowed to stir for $12 \mathrm{~h}$ at $40{ }^{\circ} \mathrm{C}$. The completion of reaction was monitored by TLC ( $100 \%$ cyclohexane). The reaction was diluted by $\mathrm{CH}_{2} \mathrm{Cl}_{2}$ and the mixture was extracted with $\mathrm{CH}_{2} \mathrm{Cl}_{2}(50 \mathrm{~mL} \times 3)$. The combined organic extracts were washed with water, brine, dried over $\mathrm{Na}_{2} \mathrm{SO}_{4}$, filtered through Celite, and evaporated. The residue was purified by GPC to afford pure 1 (10.0 $\mathrm{mg}, 84 \%)$.

\section{Characterization data Pyrenylsumanene (1)}

Mp: $255^{\circ} \mathrm{C}$; IR (KBr) v: 3039, 2895, 2780, 1396, 842, 788, 725, 683, 602, 488, $418 \mathrm{~cm}^{-1} ;{ }^{1} \mathrm{H}$ NMR $\left(\mathrm{CDCl}_{3}\right) \delta 8.68(\mathrm{~s}, 1 \mathrm{H})$, 8.20-7.99 (m, 7H), $7.71(\mathrm{~s}, 1 \mathrm{H}), 7.40(\mathrm{~s}, 1 \mathrm{H})$ 7.19-6.90 (m, $4 \mathrm{H}), 4.84$ (d, $J=19.6 \mathrm{~Hz}, 1 \mathrm{H}), 4.74$ (d, $J=19.6 \mathrm{~Hz}, 1 \mathrm{H}), 4.53$ $(\mathrm{d}, J=19.6 \mathrm{~Hz}, 1 \mathrm{H}), 3.61(\mathrm{~d}, J=19.6 \mathrm{~Hz}, 1 \mathrm{H}), 3.45$ (d, $J=19.6$ $\mathrm{Hz}, 1 \mathrm{H}), 2.94(\mathrm{~d}, J=19.6 \mathrm{~Hz}, 1 \mathrm{H}) \mathrm{ppm} ;{ }^{13} \mathrm{C} \mathrm{NMR}\left(\mathrm{CDCl}_{3}\right) \delta$ 149.22, 149.21, 149.13, 149.12, 149.02, 149.10, 148.95, 148.94, $148.93,148.73,148,30,148.18,136.84,131.62,131.19,130.95$, $130.73,127.71,127.70,127.69,127.52,127.51,127.44,126.09$, $125.86,125.77,125.19,125.09,124.97,124.67,123.52,123.40$, $123.39,123.25,42.05,41.99,41.90 \mathrm{ppm}$; anal. calcd for $\mathrm{C}_{37} \mathrm{H}_{20}$ : C, 95.66; H, 4.34; found: C, 95.38; H, 4.40; HRMS (EI) $\mathrm{m} / z$ calcd for $\mathrm{C}_{37} \mathrm{H}_{20}\left[\mathrm{M}^{+}\right]$: 464.1565 ; found: 464.1570 .

Crystallographic data have been deposited with Cambridge Crystallographic Data Centre: Deposition number CCDC986895. Copies of the data can be obtained free of charge via http://www.ccdc.cam.ac.uk/conts/retrieving.html.

\section{Supporting Information}

\section{Supporting Information File 1}

CIF file for the pyrenylsumanene crystal.

[http://www.beilstein-journals.org/bjoc/content/

supplementary/1860-5397-10-80-S1.cif]

\section{Acknowledgements}

This work was supported by Ministry of Education, Culture, Sports, Science and Technology (MEXT), Japan Science and Technology (JST (ACT-C)) and Sumitomo Chemical. We thank Prof. Masaki Kawano (POSTECH) for the crystallographic analysis.

\section{References}

1. Higashibayashi, S.; Sakurai, H. Chem. Lett. 2011, 40, 122-128. doi:10.1246/cl.2011.122

2. Amaya, T.; Hirao, T. Chem. Commun. 2011, 47, 10524-10535. doi:10.1039/c1cc12532j

3. Sygula, A. Eur. J. Org. Chem. 2011, 1611-1625. doi:10.1002/ejoc.201001585

4. Wu, Y. T.; Siegel, J. S. Chem. Rev. 2006, 106, 4843-4867. doi:10.1021/cr050554q

5. Tsefrikas, V. M.; Scott, L. T. Chem. Rev. 2006, 106, 4868-4884. doi:10.1021/cr050553y

6. Sakurai, H.; Daiko, T.; Hirao, T. Science 2003, 301, 1878. doi:10.1126/science.1088290

7. Schmidt, B. M.; Topolinski, B.; Higashibayashi, S.; Kojima, T.; Kawano, M.; Lentz, D.; Sakurai, H. Chem.-Eur. J. 2013, 19, 3282-3286. doi:10.1002/chem.201204622

8. Shrestha, B. B.; Karanjit, S.; Panda, G.; Higashibayashi, S.; Sakurai, H. Chem. Lett. 2013, 42, 386-389. doi:10.1246/cl.121273

9. Higashibayashi, S.; Tsuruoka, R.; Soujanaya, Y.; Purushotham, U.; Sastry, G. N.; Seki, S.; Ishikawa, T.; Toyota, S.; Sakurai, H. Bull. Chem. Soc. Jpn. 2012, 85, 450-467. doi:10.1246/bcsj.20110286

10. Mebs, S.; Weber, M.; Luger, P.; Schmidt, B. M.; Sakurai, H.; Higashibayashi, S.; Onogi, S.; Lentz, D. Org. Biomol. Chem. 2012, 10, 2218-2222. doi:10.1039/c2ob07040e

11. Sakurai, H.; Daiko, T.; Sakane, H.; Amaya, T.; Hirao, T. J. Am. Chem. Soc. 2005, 127, 11580-11581. doi:10.1021/ja0518169

12. Filatov, A. S.; Scott, L. T.; Petrukhina, M. A. Cryst. Growth Des. 2010, 10, 4607-4621. doi:10.1021/cg100898g

13. Wu, Y.-T.; Bandera, D.; Maag, R.; Linden, A.; Baldridge, K. K.; Siegel, J. S. J. Am. Chem. Soc. 2008, 130, 10729-10739. doi:10.1021/ja802334n

14. Morita, Y.; Nakao, S.; Haesuwannakij, S.; Higashibayashi, S.; Sakurai, H. Chem. Commun. 2012, 48, 9050-9052. doi:10.1039/c2cc33643j

15. Amaya, T.; Seki, S.; Moriuchi, T.; Nakamoto, K.; Nakata, T.; Sakane, H.; Saeki, A.; Tagawa, S.; Hirao, T. J. Am. Chem. Soc. 2009, 131, 408-409. doi:10.1021/ja805997v

16. Bando, Y.; Sakurai, T.; Seki, S.; Maeda, H. Chem.-Asian J. 2013, 8, 2088-2095. doi:10.1002/asia.201300635

17. Schmidt, B. M.; Seki, S.; Topolinski, B.; Ohkubo, K.; Fukuzumi, S.; Sakurai, H.; Lentz, D. Angew. Chem., Int. Ed. 2012, 51, 11385-11388. doi:10.1002/anie.201205757 
18. Miyajima, D.; Tashiro, K.; Araoka, F.; Takezoe, H.; Kim, J.; Kato, K.; Takata, M.; Aida, T. J. Am. Chem. Soc. 2009, 131, 44-45. doi:10.1021/ja808396b

19. Feng, Q.; Liang, M.; Dong, B.; Xu, C.; Zhao, J.; Zhang, H. CrystEngComm 2013, 15, 3623-3629. doi:10.1039/C3CE27102A

20.Wang, C.; Dong, H.; Li, H.; Zho, H.; Meng, Q.; Hu, W. Cryst. Growth Des. 2010, 10, 4155-4160. doi:10.1021/cg100863q

21. Feng, X.; Hu, J.-Y.; Tomiyasu, H.; Seto, N.; Redshaw, C.; Elsegood, M. R. J.; Yamato, T. Org. Biomol. Chem. 2013, 11, 8366-8374. doi:10.1039/C3OB41350K

22. Winnik, F. M. Chem. Rev. 1993, 93, 587-614. doi:10.1021/cr00018a001

23. Kamei, T.; Shibaguchi, H.; Sako, M.; Toribatake, K.; Shimada, T. Tetrahedron Lett. 2012, 53, 3894-3896. doi:10.1016/j.tetlet.2012.05.063

24. Tan, Q.; Higashibayashi, S.; Karanjit, S.; Sakurai, H. Nat. Commun. 2012, 3, 891. doi: $10.1038 /$ ncomms 1896

25. Higashibayashi, S.; Sakurai, H. J. Am. Chem. Soc. 2008, 130, 8592-8593. doi:10.1021/ja802822k

26. Katoh, R.; Suzuki, K.; Furube, A.; Kotani, M.; Tokumaru, K. J. Phys. Chem. C 2009, 113, 2961-2965. doi:10.1021/jp807684m

27. Crawford, A. G.; Dwyer, A. D.; Liu, Z.; Steffen, A.; Beeby, A.; Pålsson, L.-O.; Tozer, D. J.; Marder, T. B. J. Am. Chem. Soc. 2011, 133, 13349-13362. doi:10.1021/ja2006862

\section{License and Terms}

This is an Open Access article under the terms of the Creative Commons Attribution License (http://creativecommons.org/licenses/by/2.0), which permits unrestricted use, distribution, and reproduction in any medium, provided the original work is properly cited.

The license is subject to the Beilstein Journal of Organic Chemistry terms and conditions:

(http://www.beilstein-journals.org/bjoc)

The definitive version of this article is the electronic one which can be found at: doi:10.3762/bjoc. 10.80 